system for the periodic health examinution: implementation and evaluation. trch Intern. Hed 1984;144:2167-70.

8 .McPhee SJ, Bird JA, Fordham D, Rodnick JE, Osborn E. Promoting cancer prevention activities by primary care physicians: results of a randomized, controlled a

9 Chomet J, Chomet J. Cervical screening in general practice: a "new" scenario. BMf 1990;300:1504-6.

10 Fullard E, Fowler G, Gray M. Facilitating prevention in primary care. B.Mf 1984:289:1585-7.

11 Fullard E, Fowler G, Gray M. Promoting prevention in primary care: controlled trial of low technology, low cost approach. BMJ 1987;294 1080-2.

12 Mant D, McKinlay C, Fuller A, Randall T, Fullard E, Muir J. Three vea follow up of patients with raised blood pressure identified at health checks in general practice. BMF 1989;298:1360-2.

13 Imperial Cancer Research Fund OXCHECK Study Group. Prevalence of risk factors for heart disease in OXCHECK trial: implications for screening in primary care. BMF 1991;302:1057-60.

1t Srampfer MU, Buring JE Willet W, Rosner B, Eberlein $\mathrm{K}$, Hennekens $\mathrm{CH}$ The $2 \times 2$ factorial design: its application to a randomized trial of aspirin and The $2 \times 2$ factorial design: its application to a rando

15 National Cancer Institute. Working guidelines for early cancer detection: rationale and supporting evidence to decrease mortality. Bethesda, Maryland: NCI, 1987.
16 Butrum RR, Clifford CK, Lanza E. NCI dietary guidelines: rationale. Am $\mathcal{F}$ Clin Nutr 1988;48:888-95.

17 Glynn TJ, Manley MW. How to help your patients stop smoking. Bethesda, Maryland: National Institutes of Health, 1989. Publication No 89-2064

18 Dickey LL, Petitti D. Assessment of a patient-held minirecord for adult health maintenance. f Fam Pract 1990;31:431-8.

19 Neter J, Wasserman W, Kutnor MH. Applied linear statistical models. 2nd ed. Homewood, Illinois: Richard Irwin, 1985

20 Draper N, Smith H. Applied regression analysis. 2nd ed. New York, NY: John Wiley and Sons, 1981.

21 Donner A, Birkett N, Buck C. Randomization by cluster. Sample size requirements and analysis. Am $\mathcal{F}$ Epidemiol 1981;114:906-14.

22 Kleinbaum DG, Kupper LL, Morgenstern H. Epidemiologic research: principles and quantitative methods. Belmont, California: Lifetime Learning Publications, 1982:351.

23 National Cancer Institute Breast Cancer Screening Consortium. Screening mammography: a missed clinical oportunity? fAMA 1990;264:54-8.

24 American Academy of Family Physicians. Stop smoking kit. Kansas City, Missouri: AAFP, 1987.

25 Prevention program being developed aimed at primary care providers. Cancer Lett 1988;14:4

(Accepted 12 December 1991)

\title{
Randomised trial of three approaches for marketing smoking cessation programmes to Australian general practitioners
}

\author{
Jill Cockburn, Denise Ruth, Chris Silagy, Malcolm Dobbin, Yolande Reid, Michelle Scollo, \\ Lucio Naccarella
}

Abstract

Objective-To compare three approaches for marketing a quit smoking intervention kit to general practitioners.

Design-Randomised trial of $(a)$ personal delivery and presentation by an educational facilitator with a follow up visit six weeks later; $(b)$ delivery to the receptionist by a friendly volunteer courier with a follow up phone call six weeks later, or $(c)$ postal delivery with a follow up letter six weeks later.

Setting-Melbourne, Australia.

Centre for Behavioura Research in Cancer, Carlton, Victoria, Australia Jill Cockburn, PHD, senior behavioural scientist

Lucio Naccarella, BSC, evaluation officer

\section{Monash University,}

Monash, Australia

Denise Ruth, FFAFPHM, senior lecturer,

department of community medicine

Chris Silagy, FRACGP, senior research fellow, departments of social and preventive medicine and community medicine Malcolm Dobbin, PHD, postgraduate student-master of public health, department of social and preventive medicine

\section{Victorian Smoking and}

Health Program,

Melbourne, Australia

Yolande Reid, ASSOC DIP COM $\mathrm{WK}$, coordinator, health professional programme Michelle Scollo, BSC, executive director

Correspondence to: Dr Jill

Cockburn, Centre for Behavioural Research in

Cancer, Anti-Cancer

Council of Victoria, Carlton,

Victoria, Australia 3053.

BMF 1992;304:691-4
Subjects-264 randomly selected general practitioners.

Data collection-A research assistant visited each doctor four months after delivery and measured use of components of the kit. A questionnaire measuring perceptions of aspects of the kit and its delivery was completed by doctors. Costs of each approach were calculated.

Results-Doctors receiving the educational facilitator approach were significantly more likely than those receiving the other two approaches to have seen the kit, to rate the method of delivery as engendering motivation to try the kit, to have used one of the "intensive intervention" components from the kit, to report that they found the kit less complicated, and to report greater knowledge of how to use the kit. There were no significant differences in use of "minimal intervention" components of the kit, ratings of overall acceptability of delivery, perceptions of cultural and structural barriers to using the kit, and ratings of the overall acceptability of the kit. The cost of the educational facilitator approach (\$A142/doctor) was 24 times that of the mailed approach. The volunteer courier approach (\$A14) was twice the cost of the mailed approach.

Conclusion-Educational facilitators and volunteer couriers do not seem to be cost effective strategies for distributing smoking interventions.

\section{Introduction}

Given the large proportion of the population seen by general practitioners, ${ }^{1-3}$ if general practitioners were routinely to advise their smoking patients to quit even quite low rates of success would result in a substantial number of new former smokers..23 Several general practice based smoking intervention programmes are efficacious in controlled research settings, ${ }^{+6}$ but general practitioners tend not routinely to use these in actual practice. ${ }^{7}$ From a public health viewpoint general practice based smoking interventions are not reaching their maximum potential. It was this observation, together with the lack of success of a distribution procedure for their own smoking intervention programme, which led Fowler and colleagues to conclude, "The amount of energy expended in the production of [smoking] interventions must be at least equalled in marketing and dissemination." "

In Australia the Victorian Smoking and Health Program has recently faced the challenge of finding a suitable mechanism for marketing and distributing a newly developed smoking intervention programme in a way that would encourage its routine use in general practice. There were few published data on how this could best be achieved. Fowler et al distributed their brief intervention as an insert in the BMA News Review and found that few general practitioners could recall the key components of their programme. ${ }^{8}$ Other programmes have relied on attendance at introductory seminars, often with disappointing results. ${ }^{910}$

Experiences with marketing other products to general practitioners have largely centred on pharmaceuticals. Pharmaceutical representatives seem to be effective for promoting pharmaceuticals, " and academic "detailers" or "educational facilitators" have been found to be both effective and cost effective for promoting rational prescribing among general practitioners. ${ }^{12}$ There is no reported use of this approach for marketing smoking interventions to general practitioners.

We have conducted this trial to examine the effectiveness and cost effectiveness of different strategies for distributing and marketing smoking interventions to general practitioners.

\section{Subjects and methods}

A sample of general practitioners from the Melbourne metropolitan region was randomly selected from the Victorian Medical Board register. These general practitioners were randomly allocated to receive one of 
three approaches for distribution of the smoking intervention programme.

\section{SMOKING INTERVENTION PROGRAMME}

The smoking intervention programme was designed specifically for general practice and is based on strategies proved to be efficacious in research..$^{24-61314} \mathrm{It}$ is a kit which includes both a minimal intervention strategy and a more intensive strategy for people who are more motivated to quit. The patient's motivation to quit is assessed ${ }^{15}$ to determine which strategy to use. The minimal intervention (for less motivated smokers) entails the general practitioner offering simple advice to quit, together with giving the patient a comprehensive self help booklet ${ }^{16}$ and a "help" card which personalises the patient's risk factors and provides information about where the person can go for any future smoking cessation advice. More motivated people are given cessation advice within a structured framework together with a "contract" card whereby the patient makes a written contract with the general practitioner to quit smoking by a certain date. A novel resource (the QUITZ pack) is also given. This resource is shaped like a cigarette packet and contains "trivial pursuit" cards giving facts and figures about smoking, cards with coping strategies, and a "fiddlette" (comparable to worry beads). All the components of the kit are contained in a hard plastic stationery holder, which is intended to be kept on the general practitioner's desk.

\section{MARKETING APPROACHES}

The marketing approaches were as follows.

Educational facilitator-The kit was personally delivered and demonstrated to general practitioners by one of two educational facilitators from the Victorian Smoking and Health Program. Both educational facilitators had a clinical background (one as a nurse, the other as a respiratory physiologist) and received extensive training in the use of the kit and the skills necessary for encouraging general practitioners to use it. Role playing was an integral part of the training. ${ }^{1}$ The educational facilitators made appointments to see general practitioners in the same way as pharmaceutical representatives. At the initial visit the rationale for the kit and details of how to use it were explained. Concerted efforts was made to identify and overcome any reservations that the doctor might have about using the kit routinely. The doctor was also given a personally addressed letter which encouraged use of the kit and which was signed by a well known opinion leader in the movement against tobacco. A second visit was made by the educational facilitator six weeks later to encourage use and deal with any problems which had arisen.

Volunteer courier-A personally addressed and attractively packaged kit was delivered to each selected practice by a specially trained "friendly" volunteer

TABLE I - Demographic characteristics of general practitioners in three approache

\begin{tabular}{|c|c|c|c|}
\hline & $\begin{array}{c}\text { Educational } \\
\text { facilitator }\left(n=68^{\star}\right)\end{array}$ & Courier $\left(n=71^{\star}\right)$ & Mail $\left(\mathrm{n}=70^{\star}\right)$ \\
\hline Mean (SD) age (years) & $47 \cdot 9(12 \cdot 3)$ & $46 \cdot 9(10 \cdot 0)$ & $46 \cdot 4(12 \cdot 2)$ \\
\hline Mean (SD) No of patients/week & $154.4(59 \cdot 8)$ & $157 \cdot 0(60 \cdot 8)$ & $138 \cdot 6(55 \cdot 8)$ \\
\hline $\begin{array}{l}\text { Mean }(S D) \text { years in } \\
\text { practice }\end{array}$ & $19 \cdot 2(11 \cdot 7)$ & $19 \cdot 2(10 \cdot 6)$ & $16 \cdot 9(11 \cdot 4)$ \\
\hline \multicolumn{4}{|l|}{$\begin{array}{l}\text { practice } \\
\text { Size of practice: }\end{array}$} \\
\hline No $(\%)$ solo & $27(40)$ & $26(37)$ & $23(34)$ \\
\hline $\begin{array}{l}\text { No }(\%) \text { two or three } \\
\text { handed }\end{array}$ & $20(30)$ & $24(34)$ & $24(35)$ \\
\hline $\begin{array}{l}\text { No (\%) four or more } \\
\text { handed }\end{array}$ & $20(30)$ & $21(29)$ & $21(31)$ \\
\hline No $(\%)$ female & $11(16)$ & $7(10)$ & $9(13)$ \\
\hline No $(\%)$ with postgraduate qualifications & $30(44)$ & $28(39)$ & $34(48)$ \\
\hline No $(\%)$ full time & $64(94)$ & $60(87)$ & $60(58)$ \\
\hline
\end{tabular}

${ }^{\star} \mathrm{n}=$ Number of general practitioners returning questionnaires. courier. The courier received training in communication skills for interacting with receptionists. The courier made unannounced visits to the selected general practices and personally handed the package to receptionists. He explained the purpose of the kit and emphasised the importance of the general practitioner receiving it. The kit included the personally addressed letter and instructions on how to use the kit. Six weeks later a phone call to encourage use of the kit and deal with any problems was made to each general practitioner by a Victorian Smoking and Health Program employee.

Australia post-An attractively packaged kit was posted to the selected general practitioners accompanied by the personally addressed letter and instructions on how to use the kit. Six weeks later a second letter was sent to further encourage the use of the kit.

\section{DATA COLLECTION}

A research assistant visited each general practitioner's surgery a minimum of four months after the kit was received. The use of the kit was measured by counting the numbers of each component remaining in the kit and noting whether the kit had been used solely by general practitioners in the practice or whether it had been used by the receptionist or merely left in the waiting room. General practitioners were asked to complete a questionnaire which contained a number of subscales designed to measure the acceptability of the method of delivery, the degree of motivation engendered by the method of delivery, the initial reaction to the kit, an overall assessment of the acceptability of the kit for general practice, the ease of use of the kit, and an overall assessment of the informativeness of the kit. Single items measured potential barriers to the use of the kit, such as not having enough time to use it properly, cultural differences between doctor and patient, and perceptions of the complexity of the kit. Twe follow up phone calls were made and a reminder letter sent to general practitioners to maximise the return rate of the questionnaire. Ongoing records were kept of the costs of implementing each intervention. These included salaries, travel costs, telephone, and postage. Research costs and actual cost of the kit were not included.

\section{STATISTICAL ANALYSES}

Scores for subscales were calculated by summing scores on the individual items making up the subscales. Cronbach's coefficient $\alpha$ statistic, a measure of internal consistency, was used as an estimate of the reliability of subscales. ${ }^{18} \mathrm{~A}$ cut point of $>0.50$ was used as an indication of adequate reliability. ${ }^{19}$ Analyses of variance were used to test for significant differences between marketing approaches for linear variables, while $\chi^{2}$ analyses were used for categorical variables. A significance level of $\mathrm{p}<0.05$ was used.

\section{Results}

Two hundred and seventy two of the selected doctors were in active general practice in Melbourne at the time of distribution. Six doctors refused to receive the kit, and a further two refused to have the research assistant's evaluation visit. Objective usage data are available for 80 general practitioners in the educational facilitator approach, 92 in the volunteer courier approach, and 92 in the mail approach. Questionnaires were returned from 68 general practitioners in the educational facilitator approach, 71 in the volunteer courier approach, and 70 in the mail approach. The overall return rate of the questionnaire was $79 \%$.

Table I shows the demographic characteristics of general practitioners in the three approaches. There 
Educational

facilitator $(n=80)$

\begin{tabular}{llll}
$79(99)$ & $76(83)$ & $81(88)$ & 0.003 \\
$71(89)$ & $81(88)$ & $72(78)$ & $\mathrm{p}>0.05$ \\
$70(87)$ & $71(77)$ & $66(72)$ & $\mathrm{p}=0.07$ \\
\hline
\end{tabular}

No (\%) seen ki

No $(\%)$ of kits used only by general

practitioner or partner

used at least one resource ${ }^{\star}$

$70(87)$

$71(77)$

$\mathrm{p}=0.07$

*Denominator $=$ number of cases in which general practitioner was sole user of all resources (excludes general practitioners where it is known that kit was not used either solely by general practitioner or by another general practitioner in practice).

TABLE III-Mean (SD) numbers of each component used by doctors in each approach over study period ${ }^{\star}$

\begin{tabular}{|c|c|c|c|c|}
\hline & $\begin{array}{l}\text { Educational } \\
\text { facilitator }\end{array}$ & Courier & Mail & $\mathrm{p}$ Value \\
\hline $\begin{array}{l}\text { Help cards } \\
\text { Contract cards } \\
\text { QUITZ pack } \\
\text { Self help books }\end{array}$ & $\begin{array}{c}10.45(15 \cdot 30) \\
6.54(12 \cdot 59) \\
6.33(7 \cdot 12) \\
18 \cdot 64(17 \cdot 72)\end{array}$ & $\begin{array}{c}10.51(23.89) \\
3.79(10.03) \\
6.47(7.56) \\
16.95(17.33)\end{array}$ & $\begin{array}{c}7 \cdot 41(15 \cdot 79) \\
1 \cdot 92(6 \cdot 33) \\
6 \cdot 73(7 \cdot 42) \\
18 \cdot 48(17 \cdot 87)\end{array}$ & $\begin{array}{l}0.50 \\
0.02 \\
0.94 \\
0 \cdot 80\end{array}$ \\
\hline
\end{tabular}

«Excludes general practitioners where it is known that kit was not used either solely by general practitioner or by another general practitioner in practice.

were no significant differences on any of the variables examined, indicating that the samples were comparable on these characteristics.

\section{PROCESS EVALUATION}

Educational facilitator-The educational facilitator was able personally to see $99 \%$ of the general practitioners who consented to the initial visit and $85 \%$ of these general practitioners at the second visit. Of the 12 general practitioners not seen at the second visit, phone contact was made with six general practitioners, receptionist contact with five, and one general practitioner refused a follow up visit by the educational facilitator. The initial visit lasted an average of $12 \cdot 8$ (SD 5.8) minutes.

Volunteer courier - The courier was able to see 89 $(96 \%)$ of the receptionists at selected practices. He also opportunistically explained the use of the kit in person to $24(26 \%)$ of the general practitioners. Seventy one $(76 \%)$ of the general practitioners in the courier approach were able to be personally contacted for the phone call which encouraged use.

\section{ACCEPTABILITY OF METHOD OF DELIVERY}

Acceptable levels of Cronbach's $\alpha$ statistic were found for subscales which measured perceptions of overall acceptability of the method of delivery $(\alpha=$ 0.74 ) and the degree to which general practitioners thought that the method of delivery motivated them at least to try the kit $(\alpha=0 \cdot 84)$. For general practitioners who reported at least seeing the kit there was no significant difference between the marketing approaches for scores on the subscale measuring perceptions of overall acceptability. However, the educational facilitator approach was rated significantly more motivating than the other two approaches $\left(F_{2,175}=7 \cdot 99 ; \mathrm{p}=0 \cdot 0005\right)$.

\section{INITIAL REACTION TO KIT AND USE OF KIT}

The subscale which measured general practitioners' initial reactions to the kit was found to be reliable ( $\alpha=$ $0 \cdot 79)$. Though there was a trend towards the general practitioners in the educational facilitator approach having a more favourable initial reaction to the kit, this just failed to reach statistical significance $\left(F_{2,176}=2 \cdot 87\right.$; $\mathrm{p}=0.059$ ).

Table II shows, for each approach, the number of general practitioners who claimed that they had seen the kit, the number of practices where the kit was used only by general practitioners, and the number of general practitioners who had used at least one component from the kit. Significantly more general practitioners in the educational facilitator approach claimed to have at least seen the kit $\left(\chi^{2}=11 \cdot 87 ; \mathrm{df}=2\right.$; $\mathbf{p}=0.003$ ), and there was a trend towards general practitioners in this approach being more likely to have used at least one component $\left(\chi^{2}=5 \cdot 12 ; \mathrm{df}=2 ; \mathrm{p}=0.07\right)$ However, there was no significant difference between approaches as to whether the kit was used only by general practitioners in the practice.

Table III shows the mean numbers of each component which had been used by general practitioners receiving each marketing approach over the four month study period. There was no significant difference between marketing approaches for the minimal intervention components (help cards and CanQuit books) or the novel QUITZ pack. However, there was a significant difference in the number of contract cards used, general practitioners in the educational facilitator group using significantly more contract cards than general practitioners in the other two groups $\left(F_{2,234}=\right.$ $4 \cdot 12 ; \mathrm{p}=0 \cdot 02)$.

\section{BARRIERS TO USING KIT}

General practitioners in the educational facilitator group were significantly more likely to believe that the kit was less complicated $\left(F_{2,169}=4 \cdot 76 ; \mathrm{p}=0.01\right)$ and reported more knowledge on how to use the kit $\left(F_{2,167}=3.85 ; \mathrm{p}=0.02\right)$ than general practitioners receiving the other two distribution approaches. There were no significant differences between marketing approaches for other potential barriers which were measured.

\section{OVERALL REACTION TO KIT}

Acceptable $\alpha$ levels indicating reliability were found for the subscales which measured general practitioners' perceptions of their overall reaction to the kit $(\alpha=0.90)$ and their impressions of the acceptability of the kit for general practice $(\alpha=0.82)$, the ease of use of the kit ( $\alpha=$ $0.93)$, and general informativeness of the kit $(\alpha=0.77)$ There were no significant differences between the marketing approaches for any of these factors.

\section{COST OF INTERVENTIONS}

Table IV shows the costs in implementing each intervention. The cost of the educational facilitator approach (\$A142/general practitioner) was 24 times that of the mailed approach.

TABLE IV-Cost of implementing each approach $(\$ A)^{\star}$

\begin{tabular}{|c|c|c|c|}
\hline & $\begin{array}{c}\text { Educational } \\
\text { facilitator }(n=86 \dagger)\end{array}$ & Courier $(n=93 t)$ & $\operatorname{Mail}(n=93 t)$ \\
\hline $\begin{array}{l}\text { Staff training } \\
\text { Salaries } \\
\text { Secretarial } \\
\text { Clerical } \\
\text { Travel } \\
\text { Phone } \\
\text { Postage }\end{array}$ & $\begin{array}{r}1100 \\
9471 \\
70 \\
28 \\
1517 \\
53\end{array}$ & $\begin{array}{c}300 \\
420 \ddagger \\
70 \\
28 \\
430 \\
39\end{array}$ & $\begin{array}{r}90 \\
28 \\
\\
443\end{array}$ \\
\hline Total & 12239 & 1287 & 561 \\
\hline $\begin{array}{l}\text { Cost/general } \\
\text { practitioner } \\
\text { Cost relative } \\
\text { to mail }\end{array}$ & $\begin{array}{l}142 \\
24 \times\end{array}$ & 14 & 6 \\
\hline
\end{tabular}

$\star$ Costs exclude research costs.

†Original numbers before refusals.

¥Salaries for follow up phone call only; initial visit by volunteer.

\section{Discussion}

The aim of the present study was to compare the effectiveness of three approaches for marketing smoking interventions to general practitioners. Of the three approaches, the educational facilitator group scored highest on the scale measuring whether the method of delivery motivated the general practitioner to try the kit. This finding is supported by the strong 
trends among general practitioners in this group having a more favourable initial reaction to the kit and being more likely to have used the kit at least once. However, in terms of long term use the only component for which there was a significant difference between approaches was for the use of the contract card, significantly more cards being used by general practitioners in the educational facilitator approach. This might reflect that general practitioners who had been seen by educational facilitators were more likely to have used the kit as intended, by identifying patients' levels of motivation and then using the more intensive intervention involving the contract card for those patients more motivated to quit. This supposition is supported by the finding that doctors in the educational facilitator approach were more likely to report that they knew how to use the kit and that the kit was not too complicated. The educational facilitator approach therefore seems to have had a relatively greater impact on general practitioners' use of the more intensive intervention components.

However, this finding must be considered in the context of the high costs associated with this particular marketing approach and the failure to show a significant advantage above other groups for use of the minimal intervention strategies and for ratings of the overall acceptability of the kit. The educational facilitator approach cost $\$ A 142$ per general practitioner compared with $\$ \mathrm{~A} 14$ for the volunteer courier and $\$ \mathrm{~A} 6$ for the mailed approach. The added benefit in terms of smoking cessation in patients of general practitioners in the educational facilitator approach would need to be high to justify this expense.

There are some reasons that may account for the failure to detect substantial differences between approaches on some measures. Firstly, there was low overall usage of some components of the kit. It may be that these components were unacceptable to general practitioners, making it unlikely that any marketing approach would increase their use. Secondly, it is possible that the educational facilitators were not suited or skilled for their tasks. However, given the selection and extensive training programme and ongoing quality control through weekly meetings, this is thought to be unlikely. Thirdly, the educational facilitators in our study visited general practitioners on only two occasions over a relatively short period (six weeks). This level of intervention was determined by available resources. The success rate of this approach may change if the number of visits were to increase, but even if this were to occur it would conceivably be offset by the increased costs of implementation.

Given the inability of this study to show a cost effective outcome with the educational facilitator approach, this does not seem to be a realistic option for marketing smoking interventions to general practitioners. Even the friendly volunteer courier approach, which was only twice the cost of mailing, failed to produce sufficient benefit to justify this as a viable option. These results suggest that any initiatives which rely on educational facilitators as means of information dissemination and motivation for behavioural change should be subjected to trials before widespread implementation.

We thank Anne Gibbs, Michael Murphy, and Bronwyn Nixon for efficient and reliable data collection; Marco Cappiello for careful data analysis; Anne Rose and Paul Guy for carrying out the detailing with competence and enthusiasm; Russell Warren for volunteering his time as ou "friendly" courier; and the general practitioners who took part. The project was funded by the Victorian Smoking and Health Program from support given by the Victorian Health Promotion Foundation.

1 Australian Bureau of Statistics. Austrulian health survey 1983. Canberra: ABS, 1984. (Catalogue No 4311.0.

2 Russell MAH, Wilson C, Taylor C, Baker CD. Effect of general practitioners' advice against smoking. BMf 1979;ii:231-5.

3 Glynn TJ, Manley MW. Physicians, cancer control and the treatment of nicotine dependence: defining success. Health Education Research 1989;4: 479-87

4 Wilson DM, Taylor DW, Gilbert JR, Best A, Lindsav EA, Willms D, et at. A randomized trial of a family physician intervention for smoking cessation. FAMA 1988;260:1570-4.

5 Richmond RL, Austin A, Webster IW. Three year evaluation of a programme by general practitioners to help patients to stop smoking. BMf 1986;292 803-6.

6 Wilson DH, Wakefield M, Steven I, Rorsheim R, Esterman A, Graham N. "Sick of smoking": evaluation of a targeted minimal cessation intervention in general practice. Med f Aust 1990;152:518-21.

7 Dickinson JA, Wiggers J, Leeder SR, Sanson-Fisher RW. General pracitioners' detection of patients' smoking status. Med f Aust 1989;150:420-6.

8 Fowler G, Mant D, Fuller A, Jones L. The "help your patient stop" initiative Evaluation of smoking prevalence and dissemination of WHO/UICC guidelines in UK general practice. Lancet 1989;i:1253-5.

9 Copeman RC, Swannel RJ, Pincus DF, Woodhead KA. Utilization of "smokescreen" smoking cessation programme by general practitioners an their patients. Med f Aust 1989;151:83-7.

10 Silagy C. Utilization of "smokescreen" smoking cessation programme. Med Aust 1989;151:486.

11 Greenwood J. Prescribing and salesmanship. Health Action International News 1989:48:1-3.

12 Avorn J, Soumerai SB. Improving drug therapy decisions through education controlled trial of academically based "detailing." $N$ Engl f Med 1983;308 $1457-63$

13 Slama K. Smoking cessation interventions for use by general practitioners. Newcastle: University of Newcastle, 1988. (Doctoral dissertation.)

14 US Preventive Services Task Force. Counselling to prevent tobacco use. In US Prevention Task Force guide to clinical prevention services: an assessment of the effectiveness of 169 interventions. Baltimore. Williams and Wilkins, 1989:289-95.

15 Prochaska J, Di Climente C. Stages and processes of self-change in smoking: towards an integrative model of change. I Consult Clin Psychol 1983;51: $390-5$

16 Borland R, Lee A, Scollo $M$. The utility of mass distribution of a self-help resource for smoking cessation. In: Quit evaluation studies. No 5. Melbourne: Anti-Cancer Council of Victoria, 1991. (ISSN 0817-905C.)

17 Maguire P, Rox P, Goldberg D, Jones S, Hyde C, O'Dowd T. The value of feedback in teaching interviewing skills to medical students. Psychol Med 1978:8:695-704

18 Cronbach LJ. Co-efficient alpha and the internal structure of tests. Psycho-

9 Helmstadter GC. Principles of psychological measurement. New York: AppletonCentury-Crofts, 1964

Accepled 3 December 1991 